ISSN 2236-0859

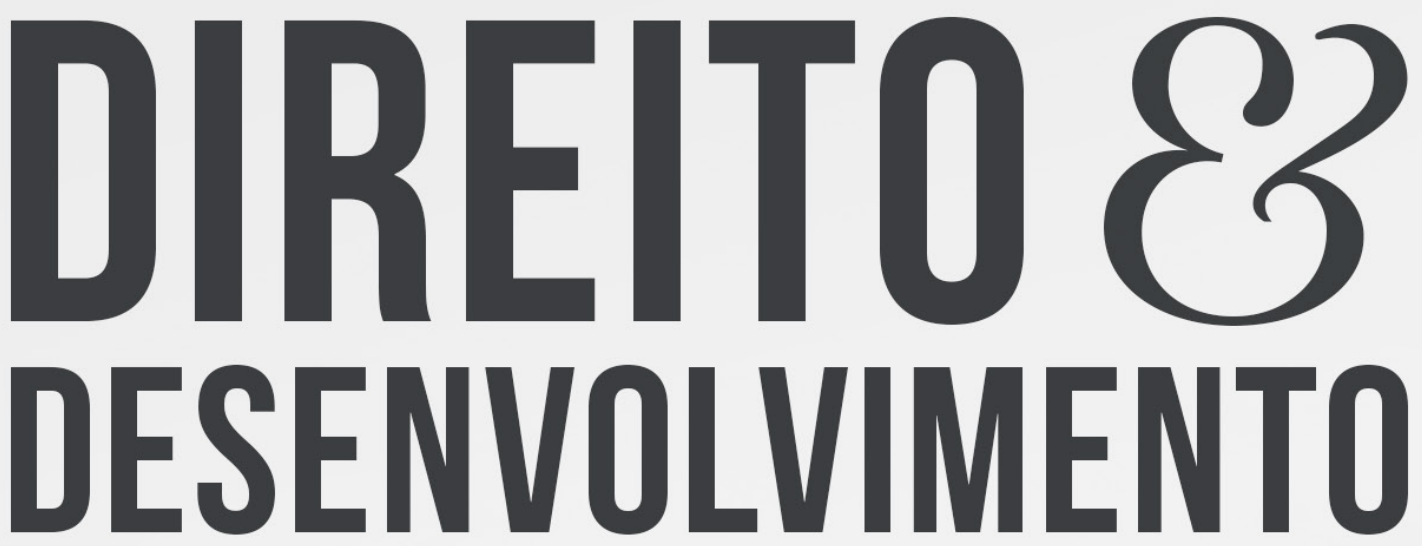

REVISTA DO PROGRAMA DE PÓS-GRADUAÇÃO EM DIREITO MESTRADO EM DIREITO E DESENVOLVIMENTO SUSTENTÁVEL

CUSTOS, INSEGURANCGA JURIDICA E TERCEIRIZAÇÃO: PERCEPÇÃODAS EMPRESAS 


\section{CUSTOS, INSEGURANÇA JURÍDICA E TERCEIRIZAÇÃO: PERCEPÇÃO DAS EMPRESAS}

\section{COSTS, LEGAL UNCERTAINTY AND OUTSOURCING: PERCEPTION OF FIRMS}

Recebido: $18 / 10 / 2018$

Aprovado: 13/12/2019
Glauco Braga Dias ${ }^{1}$

Luiz Ricardo Mattos Teixeira Cavalcante ${ }^{2}$

\section{RESUMO:}

Objetiva analisar os custos e a insegurança jurídica relacionados à terceirização no Brasil após a promulgação das Leis no 13.429/2017 e no 13.467/2017 (reforma trabalhista), que disciplinaram esse instituto no país. Em particular, analisam a percepção das empresas prestadoras de serviços à Caixa Econômica Federal (CEF). A análise fundamenta-se $i$ ) nas planilhas de composição de custos de 121 contratos de prestação de serviços mantidos pela CEF entre 2013 e 2018; e ii) em entrevistas semiestruturadas com gestores das empresas contratadas pela CEF. Demonstra-se que ainda não houve reduções de custos e de insegurança jurídica nos contratos analisados e que os reflexos das inovações legislativas devem ser verificados após a consolidação dos entendimentos jurisprudenciais sobre a terceirização (possivelmente a partir de 2020). Conclui-se, assim, que as inovações legislativas ocorridas em 2017 tenderão a favorecer a terceirização nas empresas no Brasil, porém de forma diferida.

Palavras-chave: Terceirização. Reforma trabalhista. Custo do trabalho. Insegurança jurídica. Lei no $13.467 / 2017$.

$\mathrm{K}_{31}$

\section{ABSTRACT:}

Aims to analyze costs and legal uncertainty related to outsourcing in Brazil after the enactment of Laws 13.429/2017 and 13.467/2017 (Labor Reform), which disciplined this institute in the country. In particular, we analyze the perception of the companies contracted by the Caixa Econômica Federal (CEF). The analysis is based on $i$ ) the cost composition sheets of 121 contracts maintained by the CEF between 2013 and 2018; and ii) semi-structured interviews with ten managers of companies contracted by CEF. We show that both the cost and the legal uncertainty reductions have not yet been observed and that the impact of the legislative innovations shall be verified after the period for the consolidation of jurisprudential understandings about outsourcing in Brazil (possibly after 2020). We conclude that the legislative innovations shall create incentives for outsourcing in Brazil, although in a deferred way diferida.

Keywords: Outsourcing. Labor reform. Labor cost. Juridical insecurity. Law no 13.467/2017.

1 Mestre em Administração Pública, IDP. Especialista em Direito Civil pela Universidade Cândido Mendes, UCAM. Graduado em Direito pelo Centro Universitário de Barra Mansa, UBM. Advogado. Email: gbragad@gmail.com

2 Doutor e Mestre em Administração pela UFBA. Professor do Professor do Mestrado em Administração Pública do IDP. Consultor Legislativo do Senado Federal. Email: luiz.ricardo.teixeira.cavalcante@gmail.com 


\section{INTRODUÇÃO}

A terceirização é um instituto amplamente utilizado e essencial para a competitividade das empresas em todo o mundo. Com efeito, tanto empresas privadas quanto estatais se valem largamente desse instituto para se tornar mais ágeis, eficientes e eficazes, bem como para obter aumento de qualidade e especialização, podendo culminar em incremento na competitividade de seus produtos no mercado (QUEIROZ, 1992). No Brasil, pesquisa realizada com 2.330 empresas industriais revela que quase $70 \%$ delas contratam serviços terceirizados atualmente ou os contrataram nos últimos três anos (CNI, 2014).

Contudo, embora alguns aspectos relativos à terceirização tenham sido objeto de normatização já na década de 1960, não havia, até recentemente, regulamentação consolidada sobre o assunto no país. Devido à inércia do Poder Legislativo, o instituto foi durante bastante tempo regrado pelas Súmulas do Tribunal Superior do Trabalho (TST) no 239, no 256, no 257 e no 331 (CASTRO, 2000). A Súmula do TST no 331, em particular, somente permitia, na esfera privada, a terceirização de atividades-meio (proibindo, contrário sensu, a terceirização de atividades-fim), e determinava que a empresa contratante de serviços tem responsabilidade subsidiária por eventuais verbas devidas pelo empregador a seu trabalhador (CNI, 2016). Em meio a um debate jurídico pautado na diferenciação de atividades-meio e atividades-fim, surgiram a Lei no 13.429/2017 e a Lei № 13.467/2017 (reforma trabalhista), que atualmente regulamentam o instituto no país.

Esse novo marco legal pode, em tese, contribuir para a redução dos custos e da insegurança jurídica relacionados à terceirização. Isso tende a ocorrer porque, com a nova legislação, os contornos do instituto tornam-se mais delineados, o que possivelmente irá contribuir para a diminuição do passivo trabalhista decorrente dos entendimentos divergentes sobre o tema. Contudo, embora essas consequências sejam esperadas, não há, ainda, uma avaliação do impacto efetivo da Lei no 13.429/2017 e da Lei no 13.467/2017 sobre essas variáveis.

O objetivo deste trabalho é, portanto, analisar os custos e a insegurança jurídica relacionados à terceirização no Brasil após a promulgação da Lei no $13.429 / 2017$ e da Lei no 13.467/2017, que disciplinaram esse instituto no país. Em particular, busca-se analisar esse tema no âmbito de uma empresa pública - a Caixa Econômica Federal (CEF) -, que está sujeita a restrições adicionais em relação às empresas privadas no que diz respeito à possibilidade de contratação de serviços terceirizados. A fundamentação teórica do trabalho ampara-se em uma discussão sobre custos do trabalho e insegurança jurídica, em uma revisão do conceito de terceirização sob os pontos de vista da administração e do direito e em uma discussão sobre a reforma trabalhista ocorrida no Brasil em 2017. A análise empírica fundamentase i) nas planilhas de composição de custos de 121 contratos de prestação de serviços mantidos pela CEF entre 2013 e 2018; e ii) em entrevistas semiestruturadas com gestores das empresas contratadas pela CEF, por meio das quais se buscou capturar sua percepção sobre o tema. Embora as entrevistas tenham se limitado a gestores de empresas contratadas pela CEF, os resultados obtidos neste trabalho podem ser facilmente extrapolados, uma vez que os prestadores de serviços atuam também em diversas outras empresas nas esferas Federal, Estadual e Municipal. O trabalho trata de um tema relevante para as empresas, porém pouco discutido na produção teórica em administração no Brasil e tem um caráter claramente interdisciplinar, uma vez que não é possível discutir a terceirização no Brasil com base em elementos puramente gerenciais ou econômicos, em vista dos aspectos legais envolvidos. $\mathrm{O}$ artigo está segmentado em mais quatro seções além desta introdução. Na seção 2, discutem-se o conceito de terceirização e a reforma trabalhista que ocorreu no Brasil em 2017. Em seguida, na terceira seção, estão descritos os procedimentos metodológicos adotados. Os resultados 
estão registrados na quarta seção e, na seção 5 , destacam-se as principais conclusões do trabalho.

\section{FUNDAMENTOS: TERCEIRIZAÇÃO E REFROMA TRABALHISTA}

Nesta seção, reúnem-se os fundamentos que amparam a análise dos custos e da insegurança jurídica relacionados à terceirização no Brasil após a reforma trabalhista. Esses fundamentos são segmentados em três subseções: i) custos do trabalho e insegurança jurídica; ii) terceirização; e iii) reforma trabalhista.

\subsection{Custos do trabalho e insegurança jurídica}

Os custos do trabalho podem ser segmentados em quatro grandes blocos (INTERNATIONAL CONFERENCE OF LABOUR STATISTICIANS [ICLS], 1966; BUREAU OF LABOUR STATISTICS [BLS]; 2012, CAVALCANTE, 2015): i) pagamento pelo tempo trabalhado; ii) benefícios pagos diretamente; iii) gastos previdenciários dos empregadores e outros tributos relacionados ao trabalho; e iv) custos de formação profissional e de serviços de bem-estar e custos do trabalho não classificados em outras rubricas. Os passivos trabalhistas, que envolvem vários tipos de indenizações, compõem as rubricas do terceiro bloco, que "absorve, - ao menos em tese - os custos associados à insegurança jurídica usualmente mencionada ao se analisar a legislação trabalhista do país" (CAVALCANTE, 2015, p. 14).

Pinheiro (2014) relata que a insegurança jurídica aumenta o risco e os custos das transações econômicas, distorcendo em especial o sistema de preços e o custo dos negócios, além de desestimular investimentos. De acordo com esse autor, a segurança jurídica se traduz "por uma norma jurídica estável, certa, previsível e calculável, não apenas no que tange às relações jurídicas entre particulares, mas principalmente naquelas de que participa o Estado" (PINHEIRO, 2014, p. 152). Além disso, a segurança jurídica pressupõe o respeito a preceitos gerais na interpretação e na aplicação das normas jurídicas, em especial pelo Judiciário.

Ações judiciais são caras, importam em custos com advogados e com o Judiciário, além de requererem o tempo e a atenção das partes. Em particular, em um contexto marcado por maiores níveis de insegurança jurídica e no qual não se pode antever qual será o entendimento do Judiciário sobre as condutas adotadas (por exemplo, no que diz respeito à contratação de empresas prestadoras de serviços terceirizados), os custos do trabalho tendem a aumentar.

No caso da prestação de serviços terceirizados, em tese, uma redução da insegurança jurídica motivaria uma redução das provisões para passivos trabalhistas futuros e poderia ser revertida i) em favor dos salários; ii) para a margem de lucro; ou iii) para o custo total do serviço. A definição do beneficiário dessa redução da insegurança jurídica dependeria, em grande medida, das condições de concorrência: nas circunstâncias em que o mercado de trabalho está aquecido ou em que os sindicatos têm mais força para negociar, essas reduções tendem a se reverter em aumentos de salários. Se houver um pequeno número de ofertantes do serviço, é provável que as margens de lucro aumentem. Nas circunstâncias em que o mercado de trabalho esteja desaquecido e que haja um grande número de ofertantes, é provável que eventuais reduções de custos se revertam para reduções do preço da prestação do serviço. 


\subsection{Terceirização}

O conceito de terceirização tem contornos distintos, a depender do ramo doutrinário em é analisado. Neste trabalho, importam os vieses fornecidos pelas cadeiras da administração e do direito.

Para a administração, terceirização é uma forma de gestão do processo produtivo por meio da qual é atribuída uma operação interna da organização a outra, que o fará melhor e mais barato, de modo a reduzir a estrutura organizacional, trazer mais flexibilidade e agilidade à empresa e transformando custos fixos e variáveis (CHIAVENATO, 2014). Amato Neto (1995, p. 36) conceitua a terceirização como "o ato de transferir a responsabilidade por um determinado serviço ou operação/fase de um processo de produção ou de comercialização, de uma empresa para outra(s), neste caso conhecida(s) como terceira(s)". Hindle (2008, p. 143) adota uma definição bastante abrangente, segundo a qual "terceirização é um termo usado para descrever praticamente qualquer atividade corporativa gerenciada por um fornecedor externo [...]”.

Do ponto de vista gerencial, diversos fatores influenciam a decisão quanto à terceirização ou não de uma determinada atividade requerida para o processo de produção. Por um lado, ao terceirizar determinadas atividades, a empresa contratante pode se beneficiar de menores custos (que podem decorrer, por exemplo, da especialização ou dos ganhos de escala da empresa contratada ao desempenhar a tarefa). Por outro lado, a terceirização pode também retirar da empresa a capacidade de coordenação de seus processos de produção, uma vez que pode motivar o estabelecimento de relações de desconfiança entre as partes envolvidas. Isso explica por que, no início do século XX, as etapas de produção da indústria automobilística, por exemplo, tendiam a ser concentradas em única empresa. Por outro lado, modelos de produção mais modernos - que se beneficiam das tecnologias da informação e comunicação para estabelecer uma ligação mais sólida entre fornecedores e compradores são fundamentados em redes de produção nas quais se recorre amplamente à terceirização (WOMACK; JONES; ROSS, 1992).

Heikkilä e Cordon (2002) apontam que a decisão pela terceirização permite que o ente empresarial foque seus esforços em outras atividades e confere flexibilidade a sua estrutura. Isso explica por que empresas como a Honda, a DuPont e a Nokia em diversas ocasiões optaram por terceirizar a produção de componentes relevantes ou mesmo de produtos inteiros comercializados com suas marcas. Para esses autores, a decisão quanto à terceirização ou não dependerá da análise concreta do caso.

Além disso, a insegurança jurídica pode ser de desestímulo à terceirização. Com efeito, um ambiente de incertezas leva as partes envolvidas a instituírem maior número de salvaguardas que, por sua vez, aumentam o custo de transação. Santos (2010) destaca que "importa avaliar se o custo de contratar via integração vertical possui um custo de transação menor, considerando que o nível de incerteza nessa hipótese é naturalmente menor, porquanto o padrão seja hierárquico".

De qualquer forma, conforme se pode observar, em discussões sobre esse tema em outros países, não mencionam restrições legais à terceirização como um eventual impedimento para a adoção desse modelo. Trata-se, em grande medida, de uma idiossincrasia do Brasil, uma vez que não se observam restrições como aquelas colocadas no Brasil para a terceirização (ainda que, em alguns casos, se observem restrições à intermediação de mão de obra em alguns países).

A Teoria do Direito brasileira, ao definir terceirização, via de regra o faz ressaltando que é a atribuição das atividades-meio de uma empresa à outra, para que a primeira possa se centrar em suas atividades-fim (MARTINEZ, 2012). 
Embora o Código Civil de 1916 já fizesse referência à "locação de serviços", as primeiras referências normativas de forma direta e explícita à terceirização surgiram no Brasil com o Decreto-Lei no 200/1967 e com a Lei no 5.645/1970, mas em ambos os casos, voltados apenas para a Administração Pública (BARBOSA, 2016). O Decreto-Lei no 200/1967 estatui que "a execução das atividades da Administração federal deverá ser amplamente descentralizada” (art. 10, caput) e "induz a administração estatal a desobrigar-se da realização de tarefas executivas, instrumentais, recorrendo, sempre que possível, à execução indireta”. Já a Lei no 5.645/1970 apenas exemplificou as atividades que deveriam ser, preferencialmente, objeto de execução mediante a norma mencionada anteriormente, relacionando: "atividades relacionadas com transporte, conservação, custódia, operação de elevadores, limpeza e outras assemelhadas" (art. $3^{\circ}$, parágrafo único).

Foi por meio da Lei no 6.019/1974 que o Brasil passou a contar com alguma menção à terceirização no campo privado (DELGADO, 2009). A referida norma veio tratar especificamente do trabalho temporário e mereceu críticas de juristas, por prever regras menos favoráveis do que aquelas previstas aos empregados. Esse é, por exemplo, o ponto de vista de Delgado (2009), para quem "a Lei n. 6.019, de 1974, ao gerar a figura do trabalho temporário, pareceu querer firmar tipicidade específica, inteiramente afastada da clássica relação de emprego”. Esse mesmo autor argumenta que "a jurisprudência trabalhista, entretanto, ao longo das décadas desde 1974, buscou construir um controle civilizatório sobre essa figura jurídica excepcional, trazendo-a, ao máximo, para dentro das fronteiras juslaborativas".

Posteriormente a Lei no 7.102/1983, apesar de instituir sistemática de terceirização permanente, estipulando que a vigilância ostensiva e o transporte de valores poderiam ser executados tanto por empresa especializada contratada como pelo próprio estabelecimento financeiro (art. $3^{\text {o)}}$, o fez com abrangência reduzida, para abarcar apenas a categoria dos vigilantes e o transporte de valores. Finalmente, surgiu a Lei no 8.949/1994, que acrescentou o parágrafo único ao art. 442 da CLT que aparentemente introduziu uma nova hipótese de terceirização ou ao menos fez surgir uma maciça onda de terceirizações (DELGADO, 2009). Estipulava a então inovação legislativa que "qualquer que seja o ramo de atividade da sociedade cooperativa, não existe vínculo empregatício entre ela e seus associados, nem entre estes e os tomadores de serviços daquela" (art. 442, parágrafo único), que foi, novamente, rebatido pela justiça trabalhista.

Foi nesse vácuo legislativo que o TST decidiu os rumos da terceirização no Brasil, primeiramente coibindo-a, por meio do Enunciado no 256 , e posteriormente legitimando-a para atividades não essenciais, por meio da Súmula no 331 (BIAVASCHI; DROPPA, 2011). O Enunciado no $\mathbf{2 5 6}$ foi introduzido no ordenamento jurídico brasileiro em 1986 e dispôs que "salvo nos casos de trabalho temporário e de serviços de vigilância [...], é ilegal a contratação de trabalhadores por empresa interposta, formando-se o vínculo empregatício diretamente com o tomador de serviços" (Brasil, 1986).

Impulsionado por um acirramento da pressão pela flexibilização do mercado de trabalho, que deu força à terceirização, e em meio a uma atribulada disputa entre Ministério Público do Trabalho (MPT) e Banco do Brasil (BB), quanto à necessidade ou não de realização de concurso público para atividades de limpeza e conservação, que serão tratados mais à frente, o TST foi levando a uma revisão do Enunciado em 256 em 1993 e, posteriormente, em 200o, à edição da Súmula no 331 (BIAVASCHI; DROPPA, 2011, p. 8). Essa Súmula, utilizada como parâmetro normativo ante à ausência de regulamentação legal, somente permitia, na esfera privada, a terceirização de atividades-meio (proibindo, contrário sensu, a terceirização de atividades-fim), criando uma especificidade no caso brasileiro sem um paralelo de comparação internacional. A ausência de uma definição quanto àquilo que seria efetivamente atividade-meio e àquilo que 
seria atividade-fim gerou uma enorme insegurança jurídica, uma vez que caberia ao judiciário arbitrar, nos casos concretos, se a terceirização poderia de fato ser implementada ou não.

De qualquer modo, pautado por uma necessidade fática e ante a um vácuo legislativo, o TST atuou, no que se refere à terceirização, na qualidade de legislador desde 1986. Conforme destaca Saha (2010), a Teoria do Preenchimento do Vácuo, que visa justificar o ativismo judicial, defende que, frente a inatividade de um poder, fica conferida legitimidade à atuação do Poder Judiciário. Não obstante, o ativismo judicial vem sofrendo críticas por parte da doutrina, tanto por não se coadunar com o princípio da separação de poderes quanto por evitar mudanças. Com efeito, Becattini (2015) argumenta que os magistrados que desejam atuar de maneira ativa carecem de legitimidade, visto que, ao contrário dos legisladores, não são eleitos para representação popular indireta. Assim, "a adoção de uma atitude ativista por parte dos magistrados configuraria um grave erro, capaz de abalar a segurança institucional, criando conflitos entre os poderes do Estado" (BECATTINI, 2015).

No caso da Administração Pública, os princípios do concurso público e da licitação limitam a terceirização de serviços. No primeiro caso, busca-se atender ao comando constitucional de impessoalidade, de modo que não é possível terceirizar na Administração Pública a prestação de serviços relacionados à atividade-fim do órgão, conforme doutrina e jurisprudência sobre o tema. Entende-se, inclusive, que caso um trabalhador preste serviço terceirizado à Administração Pública, não será reconhecido o vínculo de emprego, ainda que presentes todos os requisitos, ante à ausência do concurso público (Súmula 363 TST). No que se refere às licitações públicas, a Administração possui, em regra, o dever de licitar e, na maioria dos casos, o certame ocorrerá na modalidade de pregão eletrônico do tipo menor preço, visto sua aplicabilidade cogente no que se refere à serviços comuns. Neste caso, será declarado vencedor aquele detentor do menor lance global, que tiver condições de habilitação (CARVALHO FILHO, 2011, p. 304-309). A Lei no 13.303/2016 manteve os principais dispositivos de dispensa e inexigibilidade de licitação, mencionados acima, e trouxe inúmeras inovações. Contudo, o pregão continua sendo a modalidade licitatória preferencial para a aquisição de bens e serviços comuns, ou seja, aqueles produtos ou serviços "cujos padrões de desempenho e qualidade possam ser objetivamente definidos pelo edital, por meio de especificações usuais no mercado" (BRASIL, 2016).

No caso específico da CEF - cujos contratos são o objeto empírico deste trabalho -, delegam-se a terceiros os serviços considerados complementares, mediante licitação, executando seu mister principal por meio de seus empregados concursados. Entretanto, considerando o novo regramento dado pelo Decreto ํo 9.507/2018, que dispõe sobre a execução indireta, mediante contratação, de serviços da administração pública federal direta, autárquica e fundacional e das empresas públicas e das sociedades de economia mista controladas pela União, a situação tende a ser alterada. Certamente o debate ainda está longe de terminar porque, na análise de uma regra, sempre deve ser considerado todo o sistema jurídico pátrio.

\subsection{Reforma Trabalhista}

Reformas trabalhistas são um tema estreitamente relacionado aos padrões de regulação do mercado de trabalho. Trata-se de um mercado no qual as chamadas falhas de mercado (situações excepcionais que geram ineficiência) são recorrentes em virtude, por exemplo, do poder de barganha inerentemente desigual entre ofertantes (trabalhadores) e demandantes (empregadores). A presença de falhas dessa natureza torna, assim, o mercado de trabalho um objeto da intervenção estatal (YEUNG, 2017). O debate que frequentemente se coloca é sobre 
os níveis ideais de regulação: um mercado de trabalho excessivamente regulamentado tende a reduzir a demanda por mão de obra e a criar impedimentos para os ganhos de produtividade, ao passo que um mercado de trabalho pouco regulamentado tende a colocar os trabalhadores em posição de vulnerabilidade social.

Esse debate permeia a discussão sobre reformas trabalhistas em todo o mundo. No caso da União Europeia, as reformas trabalhistas, de acordo com Machado (2017) estão na ordem do dia desde 1980 e as recentes movimentações reformistas buscaram enfrentar o desemprego, modernizar as leis do trabalho ou, ainda, enfrentar a crise de 2008, primando pela forte flexibilidade e desregulação de direitos. Ainda segundo Machado (2017), as reformas europeias podem ser agrupadas em quatro grandes temáticas: $i$ ) tempo de trabalho; ii) modalidades de despedida; iii) contratos de trabalhos atípicos (prazo determinado, tempo parcial e trabalho intermitente); e iv) negociação coletiva e representação coletiva. Esse autor destaca ainda uma forte tendência à "desjuridicização da regulação da organização do trabalho em prol da negociação coletiva” (MACHADO, 2017, p. 245).

Já no caso do Brasil, as principais alterações decorrentes da Lei no 13.476/2017 podem ser sintetizadas nos seguintes pontos: i) prevalência do negociado sobre o legislado; ii) fim da ultratividade dos instrumentos coletivos; iii) exclusão do cômputo das horas in itinere na jornada de trabalho; iv) regulamentação do teletrabalho e do trabalho intermitente; e $v$ ) previsão de que a contribuição sindical passa a ser facultativa (CNI, 2017).

Ainda no caso do Brasil, restrições idiossincráticas à terceirização a colocaram, também, no foco das discussões sobre a reforma trabalhista. Com o advento da Lei no 13.429/2017, o Brasil passou a contar com uma definição legal sobre terceirização porque seu art. $2^{\circ}$ acrescentou o art. 4⿳⺈-A à Lei de Trabalho Temporário (Lei no 6.019/1974) que, a partir de então, também passou a definir a terceirização sob ótica subjetivista, segundo a qual: "empresa prestadora de serviços a terceiros é a pessoa jurídica de direito privado destinada a prestar à contratante serviços determinados e específicos" (LIMA; LIMA, 2017, p. 167).

Não obstante, o art. 2을 da Lei no 13.467/2017 já alterou o art. 4º-A acrescido à Lei no 6.019/1974 pela Lei no 13.429/2017, e trouxe uma definição objetivista, ou seja, baseada na atividade:

\footnotetext{
Considera-se prestação de serviços a terceiros a transferência feita pela contratante da execução de quaisquer de suas atividades, inclusive sua atividade principal, à pessoa jurídica de direito privado prestadora de serviços que possua capacidade econômica compatível com a sua execução (LIMA; LIMA, 2017, p. 168).
}

A distinção entre os aspectos definidores da terceirização para a Administração e para o Direito pode ser explicada quando se analisam os objetos sobre os quais se debruçam seus estudiosos. Enquanto os doutrinadores da Administração preocupam-se em estudar como a terceirização pode gerar eficiência e otimização de recursos para a empresa tomadora, os juristas se empenham, via de regra, em limitar a aplicação do instituto a fim de evitar a precarização do direito dos empregados.

Com o novo regramento, o Brasil passou a acompanhar o padrão adotado nos demais países no que se refere à possibilidade de terceirização de atividade-fim, encerrando (em tese) essa discussão. Não há dúvida de que as empresas privadas podem agora terceirizar suas atividades-fim no país.

Na recentemente decisão do STF, publicada em 12/9/2017, a dualidade de tratamento dado às atividade-meio e atividade-fim voltou à discussão, sob relatoria do Ministro Luiz Fux, no Recurso Extraordinário no 760.931, onde se registra que “a dicotomia entre 'atividade-fim' e 'atividade-meio' é imprecisa, artificial e ignora a dinâmica da economia moderna, [...]”. Nessa 
mesma decisão, pondera que "a cisão de atividades entre pessoas jurídicas distintas não revela qualquer intuito fraudulento, [...]".

Ainda assim, a reforma trabalhista foi e tem sido duramente criticada pela imprensa, por doutrinadores de Direito do Trabalho e associações atuantes na Justiça do Trabalho. Em Nota Técnica apresentada ao Senado, quando a reforma trabalhista ainda era conhecida por Projeto de Lei da Câmara (PLC) no 38, de 2017, a Associação Nacional dos Magistrados da Justiça do Trabalho (Anamatra), em conjunto com outras entidades trabalhistas como a Associação Nacional dos Procuradores do Trabalho (ANPT), a Associação Nacional dos Advogados Trabalhistas (Abrat) e o Sindicato Nacional dos Auditores Fiscais do Trabalho (Sinait), expressou seu inconformismo com as alterações. Delgado e Delgado (2017), ao examinarem as modificações introduzidas (permissão de terceirização de atividade-fim e possibilidade de tratamento salarial diferenciado entre trabalhadores da prestadora e da tomadora de serviços) chegam a fazer referência ao "viés anti-humanístico e antissocial da nova legislação".

A despeito da decisão do STF, que ratificou a validade da terceirização de atividade-fim, ante ao clamor por inconstitucionalidade de diversos trechos da nova legislação, possivelmente haverá no Brasil um grande número de recursos judiciais contrários à reforma. A tendência é que se observe, nos debates o "referente pendular" que oscila entre as extremidades mencionadas por Barbosa (2016): i) "o princípio da proteção, pois o sentido da existência do Direito do Trabalho está profundamente ligado à proteção do trabalhador como parte hipossuficiente nas relações de trabalho"; e ii) "as discussões no âmbito da sociedade sobre a necessidade de aumentar a competitividade das empresas e estimular o desenvolvimento econômico via flexibilização do Direito do Trabalho". Assim, é provável que haja, em um primeiro momento, uma fase de aumento do risco jurídico, até que se estabilize a jurisprudência sobre o tema e que se possa verificar de fato o impacto definitivo da reforma trabalhista. No âmbito da Administração Pública, é também provável que a discussão permaneça acirrada, visto que, mesmo com a publicação Decreto no 9.507/2018, haverá forte pressão por atendimento ao dever constitucional de realizar concurso público.

\section{METODOLOGIA}

Para analisar os custos e a insegurança jurídica relacionados à terceirização de serviços pela CEF após a promulgação da Lei n⿳o 13.429/2017 e da Lei no 13.467/2017 foram utilizados, no presente trabalho, dados quantitativos e qualitativos.

Os dados quantitativos foram extraídos das planilhas de composição de custos de 121 contratos de prestação de serviços de recepção (34 contratos), copeiragem (44) e atendimento telefônico (43) mantidos pela CEF entre 2013 e 2018. Todos os contratos analisados foram repactuados até 2017 e estão expressos em Reais constantes daquele ano, de modo que estão atualizados na mesma base monetária, não tendo sido necessária a aplicação de deflatores. $\mathrm{O}$ universo amostral foi definido com base nos contratos ativos em fevereiro de 2018. As vistas aos processos administrativos onde se encontram as planilhas analisadas foram formalmente solicitadas e autorizadas pela CEF. Nove desses contratos (três para cada tipo de serviço) foram assinados em data posterior à vigência das novas normas e serviram de comparação com os custos verificados anteriormente.

Os dados qualitativos foram obtidos por meio de entrevistas semiestruturadas com dez gestores com contratos ativos de prestação dos serviços de recepção, copeiragem e atendimento telefônico à CEF. A abrangência geográfica das empresas e a experiência dos gestores entrevistados está indicada na Tabela 1: 
Tabela 1 - Abrangência de atuação das empresas e experiência dos gestores entrevistados

\begin{tabular}{lll}
\hline Empresa & Estados onde possui contratos ativos atualmente & $\begin{array}{l}\text { Tempo de experiência do } \\
\text { gestor entrevistado }\end{array}$ \\
\hline A & $\begin{array}{l}\text { TO, MA, PI, CE, RN, PB, PE, AL, SE, BA, DF, GO e MG (12 } \\
\text { estados + DF) }\end{array}$ & 8 anos \\
\hline B & PE, AL, SE, BA, DF, GO, MG e SP (7 estados + DF) & 21 anos \\
\hline C & BA, DF, MG, SP, ES e RJ (5 estados + DF) & 30 anos \\
\hline & $\begin{array}{l}\text { AC, AM, RR, RO, AP, PA, TO, MA, RN, PB, PE, AL, SE, BA, } \\
\text { D }\end{array}$ & $\begin{array}{l}\text { MT, MS, DF, GO, MG, SP, ES, RJ, PR, SC e RS (24 estados } \\
\text { + DF) }\end{array}$ \\
\hline E & MT, DF, GO, MG, SP e ES (5 estados + DF) \\
\hline F & PA, PI, RN, PE, AL, SE e BA (7 estados) & 13 anos \\
\hline G & DF & 12 anos \\
\hline H & AC, AM, RR, RO, AP e PA (6 estados) & 4 anos \\
\hline I & $\begin{array}{l}\text { AC, AM, PA, TO, MA, PI, CE, RN, PB, PE, AL, SE, BA, MT, } \\
\text { MS, DF, GO, MG, SP, ES, RJ, PR, SC e RS (23 estados + DF) })\end{array}$ \\
\hline J & AP, PA, MA, BA, MG, SP, ES e PR (8 estados) & 20 anos \\
\hline
\end{tabular}

Fonte: elaboração própria.

Legenda: a identificação das empresas entrevistadas foi mantida em sigilo, mas todas prestam ou prestaram serviços terceirizados, de natureza continuada, à CEF e a outros órgãos do governo.

Por meio dessas entrevistas buscou-se capturar sua percepção sobre a reforma trabalhista e sobre as questões relacionadas ao instituto da terceirização. Embora as entrevistas tenham se limitado a gestores de empresas contratadas pela CEF, os resultados obtidos neste trabalho podem ser facilmente extrapolados, uma vez que os prestadores de serviços atuam também em diversas outras empresas nas esferas Federal, Estadual e Municipal. A escolha dos entrevistados se deu de modo a propiciar representatividade de todas as regiões do Brasil. O contato se deu via telefone, no mês de agosto de 2018, com o compromisso de anonimato do entrevistado.

\section{RESULTADOS}

Nesta seção, indicam-se os resultados obtidos com base na análise das planilhas de composição de custos dos contratos de prestação de serviços mantidos pela CEF entre 2013 e 2018 (subseção 4.1) e com base nas entrevistas com gestores de empresas que atuam nesse ramo (subseção 4.2).

\subsection{Análise das planilhas de composição de custos}

A Tabela 2 registra, para os 121 contratos analisados, a composição média dos custos dos postos de recepção, copeiragem e atendimento telefônico. A tabela registra os valores médios, mas há grandes variações regionais nos valores observados. Dessa forma, os dados 
individualizados indicam que a região Nordeste invariavelmente possui o menor custo de mão de obra terceirizada, enquanto nas regiões Sudeste, Sul e Centro Oeste encontram-se os valores mais elevados, respectivamente, para os serviços de recepção, copeiragem e atendimento telefônico.

Tabela 2 - Composição média dos custos dos postos de recepção, copeiragem e atendimento telefônico

\begin{tabular}{|c|c|c|c|c|c|c|}
\hline & \multicolumn{2}{|c|}{ Recepção } & \multicolumn{2}{|c|}{ Copeiragem } & \multicolumn{2}{|c|}{ Atendimento telefônico } \\
\hline & Valor & Part. & Valor & Part. & Valor & Part. \\
\hline Salário & $1.108,24$ & $39,36 \%$ & 970,60 & $39,86 \%$ & $1.185,16$ & $43,12 \%$ \\
\hline Adicionais & 99,30 & $3,53 \%$ & 198,94 & $8,17 \%$ & 347,74 & $12,65 \%$ \\
\hline $\begin{array}{l}\text { Encargos sociais e } \\
\text { trabalhistas }\end{array}$ & 954,67 & $33,90 \%$ & 946,17 & $38,86 \%$ & 887,89 & $32,30 \%$ \\
\hline Benefícios mensais & 369,82 & $13,13 \%$ & 407,68 & $16,74 \%$ & 262,26 & $9,54 \%$ \\
\hline Insumos diversos & 25,00 & $0,89 \%$ & 15,33 & $0,63 \%$ & 18,32 & $0,67 \%$ \\
\hline Lucro do empresário & 16,05 & $0,57 \%$ & 23,17 & $0,95 \%$ & 31,16 & $1,13 \%$ \\
\hline Despesas & 29,31 & $1,04 \%$ & 22,70 & $0,93 \%$ & 51,42 & $1,87 \%$ \\
\hline Tributos & 243,00 & $8,63 \%$ & 206,89 & $8,50 \%$ & 243,29 & $8,85 \%$ \\
\hline Total & $2.815,92$ & $100,00 \%$ & $2.434,78$ & $100,00 \%$ & $2.748,76$ & $100,00 \%$ \\
\hline
\end{tabular}

Legenda: os valores estão expressos em Reais correntes de 2017.

Conforme se pode observar, os encargos sociais e trabalhistas representam de 32,30\% a $38,86 \%$ dos custos totais (entre $74,92 \%$ e $97,48 \%$ do salário contratual). Esses percentuais são consistentes com os valores registrados na produção bibliográfica sobre o tema, com destaque para o Centro de Estudos Sindicais e de Economia do Trabalho (Cesit) da Universidade Estadual de Campinas (Unicamp) (Unicamp/Cesit, 1994 como citado em Departamento Intersindical de Estatística e Estudos Socioeconômicos [Dieese], 2007) e para a análise de Pastore (1996 como citado em Dieese, 2007). A margem de lucro do empresário (que varia entre o,57\% e 1,13\%), embora não seja uma medida da rentabilidade do capital, parece reduzida. Eventuais passivos trabalhistas (decorrentes, inclusive, da insegurança jurídica relativa à terceirização) estariam embutidos nas despesas (que não chegam a representar $2 \%$ dos custos totais) ou no lucro do empresário. Contudo, somente uma análise detalhada da forma como os empresários efetivamente geram essas planilhas poderia evidenciar como esses passivos são transferidos para a contratante e identificar as razões que explicam as margens de lucro aparentemente reduzidas. Essa análise pode ser objeto de trabalhos futuros, mas extrapola os propósitos do presente artigo.

Os dados coletados revelam ainda que a região Nordeste invariavelmente possui o menor custo de mão-de-obra terceirizada, enquanto nas regiões Sudeste, Sul e Centro Oeste encontram-se os valores mais elevados, a depender do tipo de posto. Os encargos trabalhistas oneram o contrato em torno de $35 \%$, enquanto os tributos correspondem a aproximadamente $8,6 \%$ do valor do posto.

A Tabela 3 registra o número de contratos analisados e os custos dos postos de recepção, copeiragem e atendimento telefônico relativos aos períodos anterior e posterior à reforma trabalhista. No primeiro caso, em função do razoável número de contratos, registra-se também o desvio padrão. 
Tabela 3 - Número de contratos e custos dos postos de recepção, copeiragem e atendimento telefônico (total, antes e depois da reforma trabalhista)

\begin{tabular}{|c|c|c|c|}
\hline & Recepção & Copeiragem & Atendimento telefônico \\
\hline \multicolumn{4}{|l|}{ Total } \\
\hline Número de contratos & 33 & 45 & 43 \\
\hline Custo (R\$ correntes de 2017) & $2.815,92$ & $2.434,78$ & $2.748,76$ \\
\hline Desvio padrão (R\$ correntes de 2017) & 560,94 & 333,58 & 411,60 \\
\hline \multicolumn{4}{|l|}{ Antes da reforma trabalhista } \\
\hline Número de contratos & 30 & 42 & 40 \\
\hline Custo $(\mathrm{R} \$$ correntes de 2017) & 2812,04 & 2433,12 & 2763,04 \\
\hline Desvio padrão (R\$ correntes de 2017) & 572,48 & 339,25 & 421,18 \\
\hline \multicolumn{4}{|l|}{ Depois da reforma trabalhista } \\
\hline Número de contratos & 3 & 3 & 3 \\
\hline Custo (R\$ correntes de 2017) & $2.817,21$ & $2.617,71$ & $2.658,13$ \\
\hline
\end{tabular}

Legenda: os valores estão expressos em Reais correntes de 2017.

Ao se examinar a Tabela 3, não se encontram evidências de diferenças estatisticamente significativas entre os custos totais antes e depois da reforma trabalhista. Isso ocorre porque o desvio padrão é muito elevado. Com efeito, não se pode afirmar, mesmo em uma margem de confiança muito reduzida, que os custos médios posteriores à reforma seriam inferiores ou superiores àqueles observados antes dela. As grandes variações inter-regionais de custos de mão de obra explicam os desvios padrão elevados. Com efeito, a comparação dos custos médios antes e depois da reforma trabalhista precisaria levar em conta o local onde os postos de trabalho fossem ocupados. No caso dos postos de recepção e copeiragem, cujos valores médios posteriores à reforma são maiores do que os valores médios anteriores a ela, é possível uma maior presença de regiões onde os custos são maiores nos contratos firmados após a reforma. De maneira análoga, o menor custo médio do posto de atendimento telefônico após a reforma não é estatisticamente diferente do custo anterior à reforma e pode decorrer de uma maior presença de regiões onde esses custos são menores na formação da média.

Dessa forma, não é possível verificar, neste momento, qualquer redução significativa de custos dos postos de trabalhos terceirizados. Por essa razão, foram realizadas entrevistas com gestores de empresas que prestam serviço nesse ramo de atuação para verificar se, na percepção de quem vivencia essa relação contratual, há uma expectativa em relação à reforma trabalhista.

\subsection{Entrevistas}

As entrevistas visavam a capturar a percepção dos gestores das empresas prestadoras de serviços à CEF sobre a reforma trabalhista e sobre as questões relacionadas ao instituto da terceirização.

No que se refere aos impactos advindos da reforma trabalhista, a percepção dos entrevistados pode ser resumida, de forma geral, nos pontos discutidos a seguir.

A possibilidade de imputar honorários de sucumbência ao empregado foi o benefício mais citado, por mais de $70 \%$ dos entrevistados, segundo os quais já foi possível verificar uma 
redução entre 50\% e 68\% no número de novas ações. Trata-se de alteração na regra da gratuidade da justiça, que agora, nos termos trazidos pela Reforma Trabalhista, prescinde de comprovação de salário igual ou inferior a 40\% do limite máximo do Regime Geral de Previdência Social (RGPS). Argumenta-se que, a partir dessa alteração, os advogados dos reclamantes pensam mais profundamente acerca da real existência dos direitos pedidos, visto que seus clientes serão compelidos a pagar pela parcela denegada.

Os entrevistados mencionaram também a jornada intermitente como um dos benefícios da reforma. Os gestores alegam que a relação de trabalho era muito engessada, pois muitas vezes o empregado não é necessário por oito horas diárias, mas só existia essa possibilidade de contratação. Agora não mais, pois é possível contratar até por hora trabalhada.

A ausência de necessidade de homologação sindical no caso de rescisão do contrato de trabalho e o aumento dos requisitos de equiparação salarial também foram citados, mas em menos de $30 \%$ das entrevistas.

Os gestores entrevistados argumentam, de forma geral, que a permissão de terceirização de atividade-fim trará melhoria para a qualidade do serviço público, pois, de maneira geral, as empresas privadas, com sua visão empreendedora, prestam serviço com mais qualidade do que os agentes públicos.

Foi unânime, entre os gestores entrevistados, a percepção de que as inovações legislativas vieram no sentido de reduzir o risco jurídico das relações decorrentes da prestação de serviços terceirizados. Não obstante, é pacífico entre eles também que as mudanças não serão sentidas de maneira imediata. Faz-se necessário um período de estabilização da jurisprudência, visto que todos os gestores mencionaram receio na aplicação dos novos institutos trazidos pela reforma trabalhista até que os juízes se posicionem. O prazo previsto de estabilização da jurisprudência verificado nas entrevistas variou bastante (entre um e vinte anos).

O reflexo financeiro decorrente da redução do risco jurídico suscitou opiniões divergentes. Todos concordam que, ao minimizar o risco, ao menos em tese, o custo de prestação de serviços deveria diminuir. Além disso, contatou-se que:

- Para 30\% dos entrevistados, não há espaço para que a redução de risco seja refletida no custo. Isso se deve ao fato de que a margem de lucro das empresas prestadoras de serviços terceirizados está reduzida ao máximo, devido à alta concorrência verificada nos certames licitatórios.

- Para a maioria (70\%), haverá uma redução nos custos de prestação de serviços. Argumentou-se que de fato há uma alta competição entre as empresas que prestam serviços terceirizados para o governo e que não há campo específico para provisionamento do risco jurídico nas planilhas de composição de custos. No entanto, ponderou-se que o custo da equipe jurídica (assim como dos processos judiciais) está alocado no item de despesas administrativas, que será reduzido se diminuírem o número de ações. Ademais, foi mencionado que normalmente há contratos bons e contratos ruins (que geram muitos litígios), de modo que um contrato acaba compensando o outro. No que se refere ao custo permanente com despesa administrativa, o entrevistado da empresa I mencionou que há hoje uma equipe de 18 advogados dedicados a tratarem de reclamações trabalhistas.

Não obstante, mesmo tendo havido expressiva maioria no sentido de que haverá redução do custo da prestação de serviços, isto não deve ocorrer rapidamente. O mesmo argumento foi apresentado por entrevistados de duas empresas que prestam serviços em quase todo o território nacional. Segundo estes gestores, os trabalhadores terceirizados raramente acionam judicialmente as empresas enquanto estão com seus contratos de trabalho vigentes, fazendo-o 
apenas quando têm seus contratos rescindidos. O turnover dessas duas empresas situa-se entre 36 e 18 meses, respectivamente.

A esse período soma-se o tempo necessário para que os processos sejam julgados na Justiça do Trabalho. Segundo dados do CNJ, um processo trabalhista leva, em média, 11 meses no primeiro grau e 8 meses no segundo (Figura 1).

Figura 1 - Tempo médio do processo baixado na Justiça do Trabalho

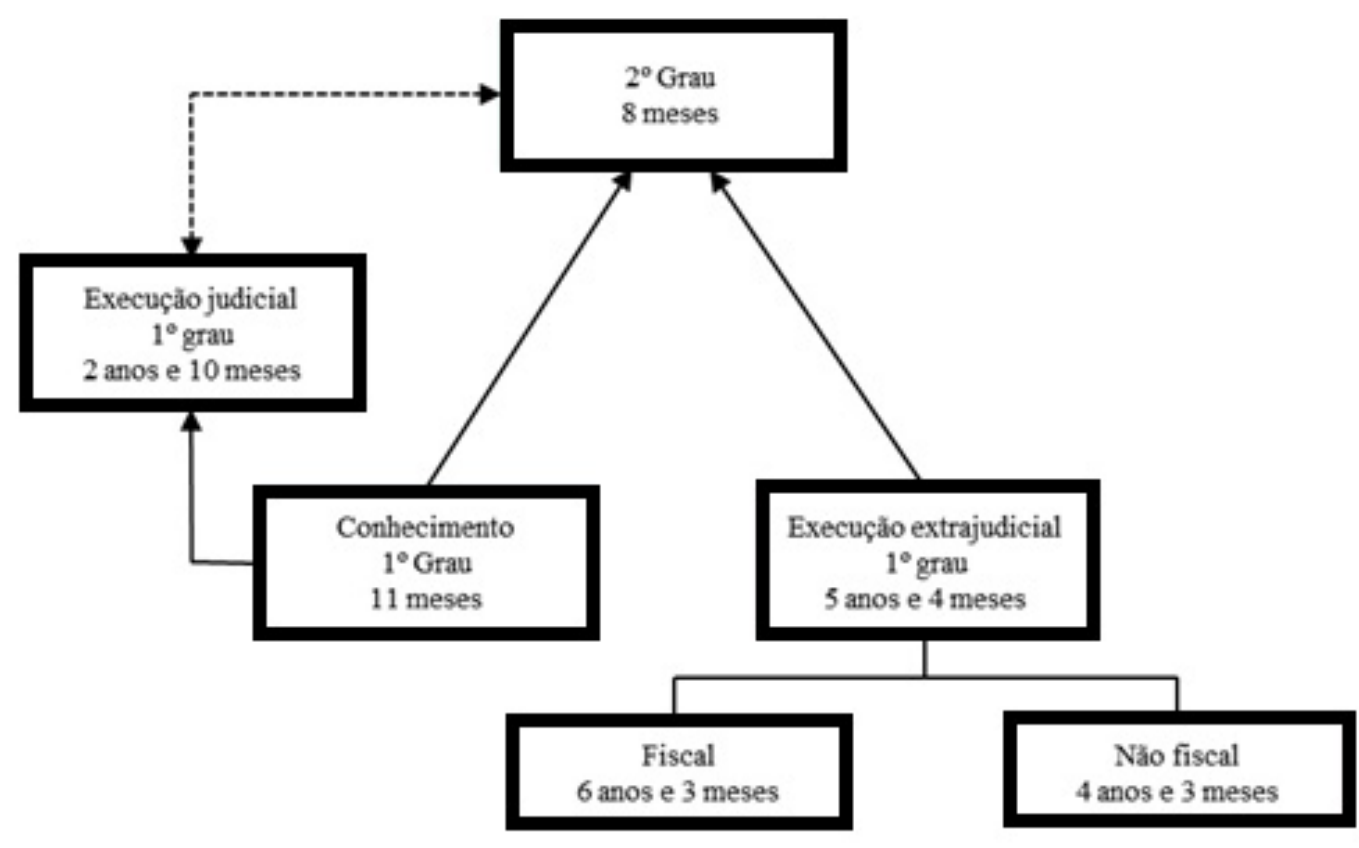

Fonte: recuperado de "Justiça em números 2018" do Conselho Nacional de Justiça, 2018, p. 38.

Assim, considerando o início da vigência da Lei da reforma trabalhista em julho de 2017, faz-se premente aguardar o surgimento das primeiras controvérsias, que normalmente surgem após o término do contrato laboral (turnover), e computar o prazo processual de primeiro e segundo grau. Destarte, tendo em vista o relatado nas entrevistas e o tempo médio estimado pelo CNJ, os impactos são esperados entre 37 e 55 meses, ou seja, entre 2020 e 2022. Dessa forma, embora ainda não tenha havido reduções de custos e de insegurança jurídica nos contratos analisados, os reflexos das inovações legislativas devem ser verificados após a consolidação dos entendimentos jurisprudenciais sobre a terceirização (possivelmente a partir de 2020).

As entrevistas indicam que, possivelmente haverá uma fase de aumento do risco jurídico, até que haja a estabilização da jurisprudência sobre o tema e que se possa verificar de fato o impacto definitivo da reforma trabalhista. Trata-se de um cenário parecido com a curva indicada na Figura 2. 
Figura 2 - Insegurança jurídica relacionada ao instituto da terceirização após a reforma trabalhista

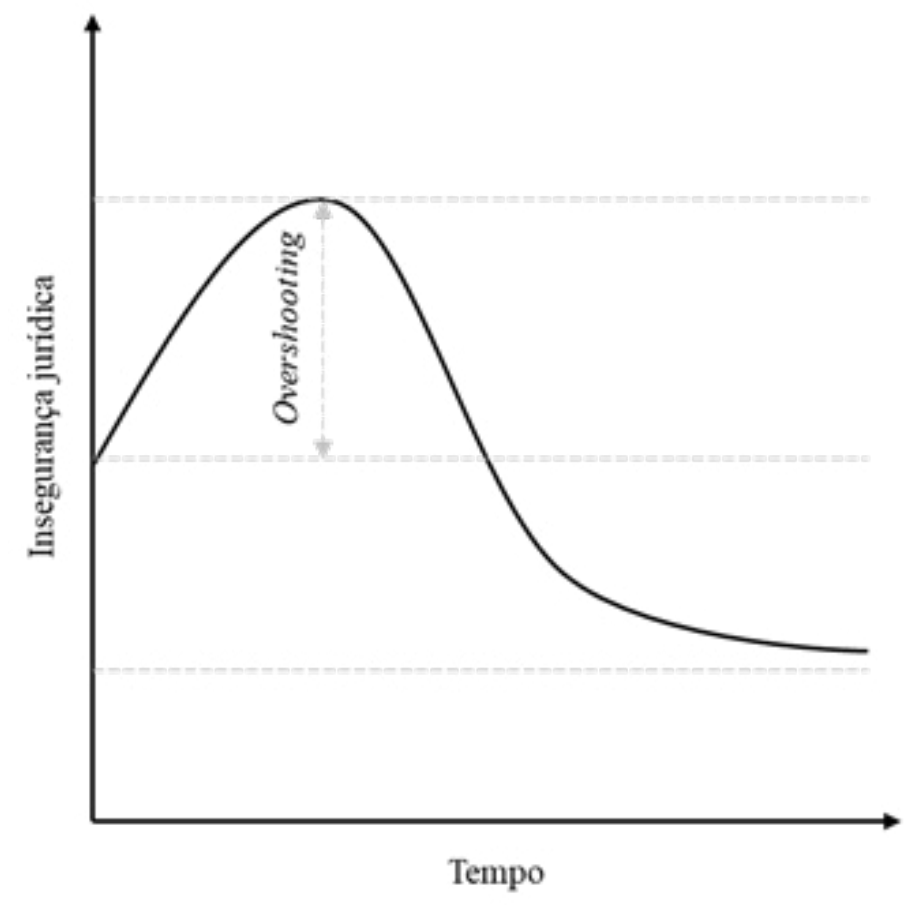

Fonte: elaboração própria.

Desta forma, considerando que um ambiente de incertezas leva as partes envolvidas a instituírem maior número de salvaguardas que, por sua vez, aumentam o custo de transação, num primeiro momento após a reforma trabalhista, é possível supor que não haverá redução dos valores pagos como remuneração à prestação de serviços terceirizados. Tais reflexos financeiros apenas serão efetivamente percebidos quando a incerteza reduzir e o mercado, sentindo essa estabilização e sendo naturalmente mais eficiente, conseguir revisar sua precificação.

Os entrevistados indicaram, ainda, os principais assuntos que foram objeto de demanda de seus empregados junto ao Judiciário Trabalhista:

- Equiparação salarial, motivada por desvios de função praticados pela Contratante ou por auxiliares que buscam igualdade de salário com o do profissional responsável;

- Horas extras; e

- Adicionais de periculosidade e insalubridade.

Pelo exposto, verifica-se que a reforma trabalhista decerto não irá mitigar os problemas trazidos pelos gestores entrevistados. O regime protetivo das MPE encontra-se em legislação que não foi alterada, enquanto que a declaração de inexequibilidade de preços, a elaboração de repactuação e a ingerência dependem de atuação por parte dos agentes públicos, enquanto que a proibição de lançamento do CSLL e IRPJ encontra-se pacificada na doutrina do TCU. Não obstante, a pesquisa foi contundente quanto ao aspecto positivo das inovações trazidas pelo novo diploma legal no que se refere à redução do risco jurídico para as empresas prestadoras de serviço terceirizado. 


\section{CONCLUSÃO}

Este trabalho objetivou analisar os aspectos relacionados aos custos e à insegurança jurídica ligados à terceirização no Brasil buscando, em particular, discutir os impactos da Lei no 13.429/2017 e da Lei no 13.467/2017 (reforma trabalhista) nessas variáveis. A hipótese que norteou a elaboração do trabalho é que as inovações legislativas produzidas em 2017 podem contribuir para diminuir tanto a insegurança jurídica quanto o custo da prestação de serviços terceirizados no país. Para verificar essa hipótese, analisaram-se as planilhas de composição de custos de 121 contratos de prestação de serviços mantidos pela CEF entre 2013 e 2018 e realizaram-se entrevistas semiestruturadas com dez gestores das empresas contratadas pela CEF, por meio das quais se buscou capturar sua percepção sobre o tema.

O trabalho trata de um tema relevante, porém pouco discutido na produção teórica em administração no Brasil e tem um caráter claramente interdisciplinar. Além disso, seus resultados podem ser facilmente extrapolados, uma vez que os prestadores de serviços analisados atuam também em diversas outras empresas.

O instituto da terceirização apenas veio a ser positivado no Brasil em 2017, o que ocasionou um grande ativismo judicial até então. A Lei no 13.429/2017 trouxe a definição do instituto ao ordenamento legal do país, mas não avançou em sua regulamentação. Já a Lei no 13.467/2017 estipulou diversas regras que dividem opiniões, sendo acusada, de um lado, de promover a precarização do trabalho e, de outro, sendo defendida por aqueles que entendem que trouxe equilíbrio para a relação judicial e auxiliará na abertura de novas vagas de emprego.

De qualquer forma, com o novo regramento, o Brasil passou a acompanhar o padrão adotado nos demais países no que se refere à possibilidade de terceirização de atividade-fim, encerrando (em tese) essa discussão. Não parece haver dúvida de que as empresas privadas podem agora terceirizar suas atividades-fim no país. Contudo, no que se refere à Administração Pública, provavelmente a discussão permanecerá acirrada, visto que, mesmo com a publicação Decreto no 9.507/2018, haverá forte pressão por atendimento ao dever constitucional de realizar concurso público.

Com base nas planilhas de composição de custos, constatou-se que ainda não há evidência de que as inovações legislativas tenham impactado os custos da prestação de serviços à CEF. Com base nas entrevistas, contudo, foi possível observar que o risco jurídico existente, que seria combatido com a positivação do instituto, tende a aumentar em primeiro momento. Isso decorre da resistência de doutrinadores e de associações de classes que atuam na Justiça do Trabalho (como a Anamatra), que expressaram seu descontentamento com as alterações que foram trazidas pela reforma trabalhista. Esse embate judicial foi citado nas entrevistas como um dos maiores temores dos empresários ligados ao setor, que devem aguardar um período de estabilização até que haja a aplicação plena das inovações trazidas ao cenário nacional. Após a consolidação dos entendimentos jurisprudenciais, acredita-se que as empresas deverão ajustar seu aparelhamento de resposta às reclamações trabalhistas e os provisionamentos de risco jurídico, de modo que as despesas tenderão a se reduzir e a economia poderá ser repassada ao usuário final. Dessa forma, os reflexos das inovações legislativas devem ser verificados de maneira diferida, principalmente em decorrência do período para a consolidação dos entendimentos jurisprudenciais pelas Cortes Superiores. 


\section{REFERÊNCIAS}

AMATO NETO, J. Reestruturação industrial, terceirização e redes de subcontratação. Revista de Administração de Empresas, v. 35, n. 2, p. 33-42, 1995.

BARBOSA, A. M. S. Terceirização: Um Objeto de Luta Político-Cognitiva no Campo Jurídico Brasileiro. Dados - Revista de Ciências Sociais, v. 59, n. 2, p. 481-516, 2016.

BECATTINI, S. R. B. Dilemas da atuação do poder judiciário: Ativismo judicial sob a ótica do pensamento de Ronald Dworkin. Belo Horizonte: D’Plácido, 2015.

BIAVASCHI, M. B.; DROPPA, A. A história da Súmula 331 do Tribunal Superior do Trabalho: a alteração na forma de compreender a terceirização. Mediações, v. 16, n. 1, p. 124-141, 2011.

BRASIL. Decreto-Lei no $\mathbf{2 0 0}$, de 25 de fevereiro de 1967. Dispõe sobre a organização da Administração Federal, estabelece diretrizes para a Reforma Administrativa e dá outras providências. Disponível em: <www.planalto.gov.br>. Acesso em: 24 jun. 2018.

Enunciado no 256, de 30 de setembro de 1986. CONTRATO DE PRESTAÇÃO DE SERVIÇOS. LEGALIDADE (cancelada) - Res. 121/2003, DJ 19, 20 e 21.11.2003. Disponível em: $<$ www.tst.jus.br>. Acesso em: 24 jun. 2018.

Lei no 13.303, de 30 de junho de 2016. Dispõe sobre o estatuto jurídico da empresa pública, da sociedade de economia mista e de suas subsidiárias, no âmbito da União, dos Estados, do Distrito Federal e dos Municípios. Disponível em: <www.planalto.gov.br $>$. Acesso em: 17 abr. 2018.

BUREAU OF LABOUR STATISTICS. International comparisons of hourly compensation costs in manufacturing, 2012. Disponível em <http://www.bls.gov/news.release/pdf/ichcc.pdf>. Acesso em: 17 abr. 2018.

CASTRO, R. F. A terceirização no direito do trabalho. São Paulo: Malheiros, 2000.

CAVALCANTE, L. R. Custos do trabalho: uma análise da indústria brasileira no período 1996-2012. Rio de Janeiro: Ipea, 2015. [Texto para discussão 2050].

CHIAVENATO, I. Introdução à teoria geral da administração. Rio de Janeiro: Campus, 2014.

CONFEDERAÇÃO NACIONAL DA INDÚSTRIA (CNI). Terceirização: o imperativo das mudanças. Brasília: CNI, 2014. Disponível em: <www.portaldaindustria.com.br $>$. Acesso em: 10 mar. 2018.

CONFEDERAÇÃO NACIONAL DA INDÚSTRIA (CNI). Terceirização: Principais pontos em debate no Brasil comparativamente à realidade de outros países. Brasília: CNI, 2016. Disponível em: <www.portaldaindustria.com.br>. Acesso em: 10 mar. 2018. 
CONFEDERAÇÃO NACIONAL DA INDÚSTRIA (CNI). Modernização trabalhista: Lei no 13.467 de 13 de julho de 2017: panorama anterior e posterior à aprovação (atualizado com as modificações da MP 808/2017). Brasília: CNI, 2017. Disponível em: <www.portaldaindustria. com.br>. Acesso em: 10 mar. 2018.

CONSELHO NACIONAL DE JUSTIÇA (CNJ). Justiça em números 2018. Brasília: CNJ, 2018. Disponível em: <http://www.cnj.jus.br/files/conteudo/ arquivo/2018/o8/44b7368ec6f888b383f6c3de40c32167.pdf>. Acesso em: 10 mar. 2018.

DELGADO, M. G. Curso de direito do trabalho. São Paulo: LTr, 2009.

DELGADO, M. G.; DELGADO, G. N. A reforma trabalhista no Brasil: com os comentários à Lei n. 13.467/2017. São Paulo: LTr, 2017.

DEPARTAMENTO INTERSINDICAL DE ESTATÍSTICA E ESTUDOS SOCIOECONÔMICOS (DIEESE). Relações e condições de trabalho no Brasil. São Paulo: DIEESE, 2007.

HEIKKILÄ, J.; CORDON, C. Outsourcing: a core or non-core strategic management decision? Wiley InterScience, p. 183-192, 2002.

HINDLE, T. The Economist Guide to Manaement Ideas and Gurus. London: The Economist Newspaper, 2008.

INTERNATIONAL CONFERENCE OF LABOUR STATISTICIANS. Resolution concerning statistics of labour cost. In: International Conference of Labour Statisticians, 11. Geneva: ICLS, 1966.

LIMA, F. M. M.; LIMA, F. P. R. M. Reforma trabalhista: entenda ponto a ponto. São Paulo: LTr, 2017.

MACHADO, S. A reforma trabalhista no brasil a partir de uma perspectiva comparada das reformas na união europeia. Revista TST. São Paulo, v. 83, n. 3, jul/set 2017, p. 239-250.

MARTINEZ, L. Curso de direito do trabalho: relações individuais, sindicais e coletivas do trabalho. São Paulo: Saraiva, 2012.

PINHEIRO, A. C. A justiça e o custo Brasil. Revista USP, n. 101, p. 141-158, 2014.

QUEIROZ, C. A. R. S. Manual de terceirização: onde podemos errar no desenvolvimento e na implantação dos projetos e quais são os caminhos do sucesso. São Paulo: STS, 1992.

SAHA, A. Judicial activism in india: a necessary evil. Jodhpur (Îndia): National Law University, 2008. Disponível em: <https://ssrn.com/abstract=1156979>. Acesso em 24 jun. 2018.

SANTOS, D. P. F. Terceirização de serviços pela administração pública: estudo da responsabilidade subsidiária. São Paulo: Saraiva, 2010. 
WOMACK, J. P.; JONES, D. T.; ROSS, D. A máquina que mudou o mundo. Rio de Janeiro: Campus, 1992.

YEUNG, L. L. Pró-devedor ou pró-credor? Medindo o viés dos juízes brasileiros. São Paulo: FEA-RP/USP, 2010. Disponível em: <https://www.fearp.usp.br/images/pesquisa/Anexos/ Publicacoes/Textos_discussao/REC/2010/TD-E13-2010.pdf>. Acesso em 24 jun. 2018. 